\title{
Differential expression and regulation of Cryab in mouse uterus during preimplantation period
}

\author{
Xue-Chao Tian, Qu-Yuan Wang ${ }^{1}$, Dang-Dang Li, Shou-Tang Wang, Zhan-Qing Yang, Bin Guo and \\ Zhan-Peng Yue \\ College of Veterinary Medicine, Jilin University, Changchun 130062, People's Republic of China and ${ }^{1}$ Department of \\ Gynaecology and Obstetrics, the Second Hospital of Jilin University, Changchun, People's Republic of China \\ Correspondence should be addressed to B Guo; Email: guobin-1979@hotmail.com; Z-P Yue; Email: yuezp@jlu.edu.cn
}

X-C Tian and Q-Y Wang contributed equally to this work

\begin{abstract}
The aim of this study was to examine the expression and regulation of the crystallin, alpha B (Cryab) gene in mouse uterus during the peri-implantation period by in situ hybridization and real-time PCR. There was no detectable Cryab mRNA signal on days 1-4 of pregnancy. On day 5 of pregnancy when embryo implanted, a high level of Cryab mRNA signal was found in the subluminal stroma surrounding the implanting blastocyst. On days 6-8, Cryab mRNA was strongly expressed in the primary decidua. By real-time PCR, a high level of Cryab expression was detected on days 7 and 8 of pregnancy, although Cryab expression was seen from days 1 to 8 . Under in vivo and in vitro artificial decidualization, Cryab expression was significantly elevated. Compared with the progesterone-primed delayed implantation uterus, a high level of Cryab mRNA expression was observed in estrogen-activated implantation uterus. In the uterine stromal cells, cAMP, estrogen, and progesterone could induce the expression of Cryab gene. In the ovariectomized mouse uterus, estrogen could also induce the expression of Cryab while progesterone inhibited its expression. Our data suggest that $\mathrm{Cryab}$ may play an important role during mouse embryo implantation and decidualization and that estrogen and progesterone can regulate the expression of Cryab gene.

Reproduction (2013) 145 577-585
\end{abstract}

\section{Introduction}

Embryo implantation is a critical initial step in the establishment of a successful pregnancy (Cakmak \& Taylor 2011). Accumulating data have shown that heatshock proteins (HSPs), a family of highly conservative multifunctional polypeptides that are classified into HSPH1 (HSP105), HSP90, HSPD1 (HSP60), and other small HSPs according to molecular weight, are closely related to embryo implantation and decidualization (Neuer et al. 2000, Yuan et al. 2009). During the menstrual cycle, HSP90 and HSP70 were expressed in human endometrium (Tabibzadeh \& Broome 1999, Neuer et al. 2000). Injection of antisense oligodeoxynucleotides to $\mathrm{HSPH} 1$ into the rat uterine horn could obviously reduce the number of implanted embryos (Yuan et al. 2009). In addition, small HSPs have been thought to play a role in decidualization (Bany \& Schultz 2001).

Alpha-crystallins, the principal members of small HSP family, comprise two types of highly homologous subunits, crystallin, alpha A (CRYAA, also known as HSPB4), and crystallin, alpha B (CRYAB, also known as
HSPB5), which are $\sim 60 \%$ identical in amino acid sequence and are encoded by two separate, unlinked genes (Robinson \& Overbeek 1996, Brady et al. 1997). CRYAA is a lens-specific protein that could protect proteins from aggregation in the eye lens, while CRYAB which was originally discovered in the mammalian eye lens as the B-subunit of $\alpha$-crystallin is also expressed in a number of non-lenticular tissues, including the heart, skeletal muscles, kidney, lung, brain, placenta, and uterus (Robinson \& Overbeek 1996, Gruidl et al. 1997, Mineva et al. 2008, Mainz et al. 2012). In term human placental tissues, $C R Y A B$ was visibly observed in the stromal cells of the placental villi (Mineva et al. 2008). In equine endometrium, CRYAB was detected on days 12 and 13.5 of pregnancy (Klein et al. 2010, Merkl et al. 2010). During the menstrual cycle, CRYAB was expressed in human and baboon endometrium and also upregulated during the window of implantation (Gruidl et al. 1997). According to our (unpublished) microarray data, Cryab expression was significantly higher in mouse uterus at implantation sites rather than at interimplantation sites. However, the expression and regulation of Cryab in mouse uterus during implantation 
and decidualization has not been defined so far. Thus, this study was undertaken to examine the expression and regulation of Cryab gene in mouse uterus during the peri-implantation period by in situ hybridization and real-time PCR.

\section{Results}

\section{Cryab mRNA expression during early pregnancy}

In situ hybridization was used to examine the spatial distribution of Cryab mRNA expression in mouse uterus (Fig. 1A). There was no detectable Cryab mRNA signal on days 1-4 of pregnancy. On day 5 of pregnancy, a high level of Cryab mRNA signal was found in the subluminal stroma immediately surrounding the implanting blastocyst, whereas no signal was detected in the interimplantation area. From days 6 to 8, Cryab mRNA signal was detected in the primary decidua at a high level and gradually increased as the decidua developed. No Cryab signals were seen in the embryos from days 5 to 8 of pregnancy by in situ hybridization.

To verify Cryab mRNA expression, real-time PCR was also performed. A high level of Cryab expression was detected on days 7 and 8 of pregnancy, although Cryab expression was seen from days 1 to 8 (Fig. 1B). Compared with the interimplantation sites, Cryab mRNA expression was higher at implantation sites on day 5 of pregnancy (Fig. 1C).

\section{Cryab mRNA expression during pseudopregnancy}

To address whether Cryab expression was dependent on embryos, we examined the expression of Cryab during pseudopregnancy. In situ hybridization results showed that there was no detectable Cryab mRNA signal in the uteri from days 1 to 5 of pseudopregnancy (Fig. 2A, B, C, and D). However, Cryab expression was relatively high on day 3 of pseudopregnancy by real-time PCR, although Cryab expression was detected from days 1 to 5 (Fig. 3A).

\section{Cryab mRNA expression during delayed implantation and activation}

In order to see whether Cryab expression was dependent on activation status of blastocyst, we examined its expression in the delayed-implantation uterus or activated implantation sites. Under delayed implantation, Cryab mRNA was not detected in mouse uterus (Fig. 2E). Once delayed implantation was terminated by estrogen treatment, Cryab mRNA signal was detected in the subluminal stromal cells surrounding the implanting embryo (Fig. 2F). Simultaneously, a significantly high
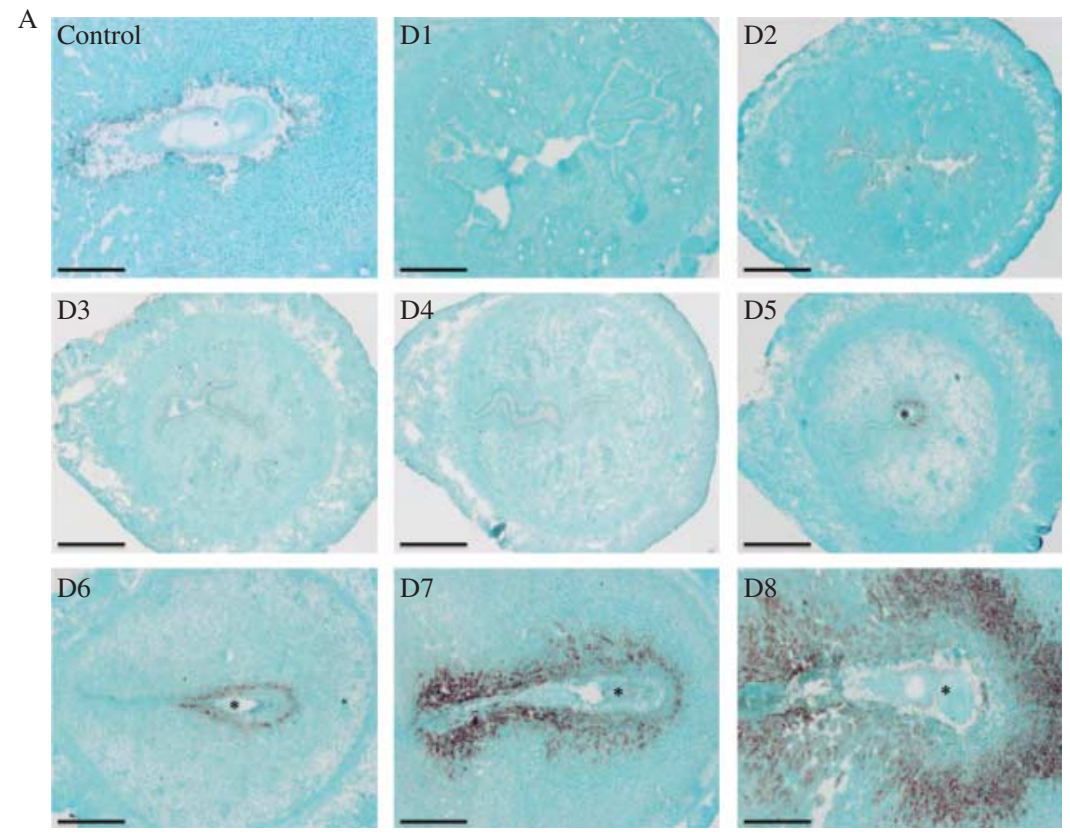

B C
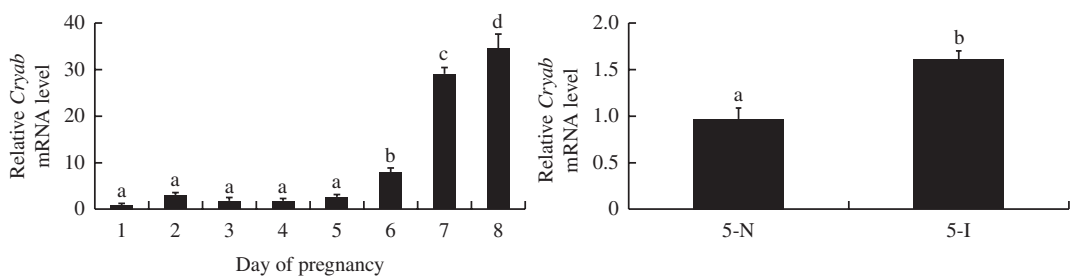

Reproduction (2013) 145 577-585
Figure 1 Cryab expression during early pregnancy. (A) In situ hybridization of Cryab expression in mouse uteri during early pregnancy on days $1,2,3$, $4,5,6,7$, and 8 . No hybridization signals were seen in mouse uterus on day 8 of pregnancy when DIGlabeled Cryab sense probe was used to replace the antisense probe as a negative control. Asterisks indicate embryo Bar $=60 \mu \mathrm{m}$. (B) Real-time PCR analysis of Cryab expression in mouse uterus on days 1-8 during pregnancy. (C) Real-time PCR analysis of $C r y a b$ expression at the implantation sites (5-I) and interimplantation sites (5-N) on day 5 of pregnancy. Data are shown as mean \pm s.E.M. Bars with different letters at the top differ significantly. 

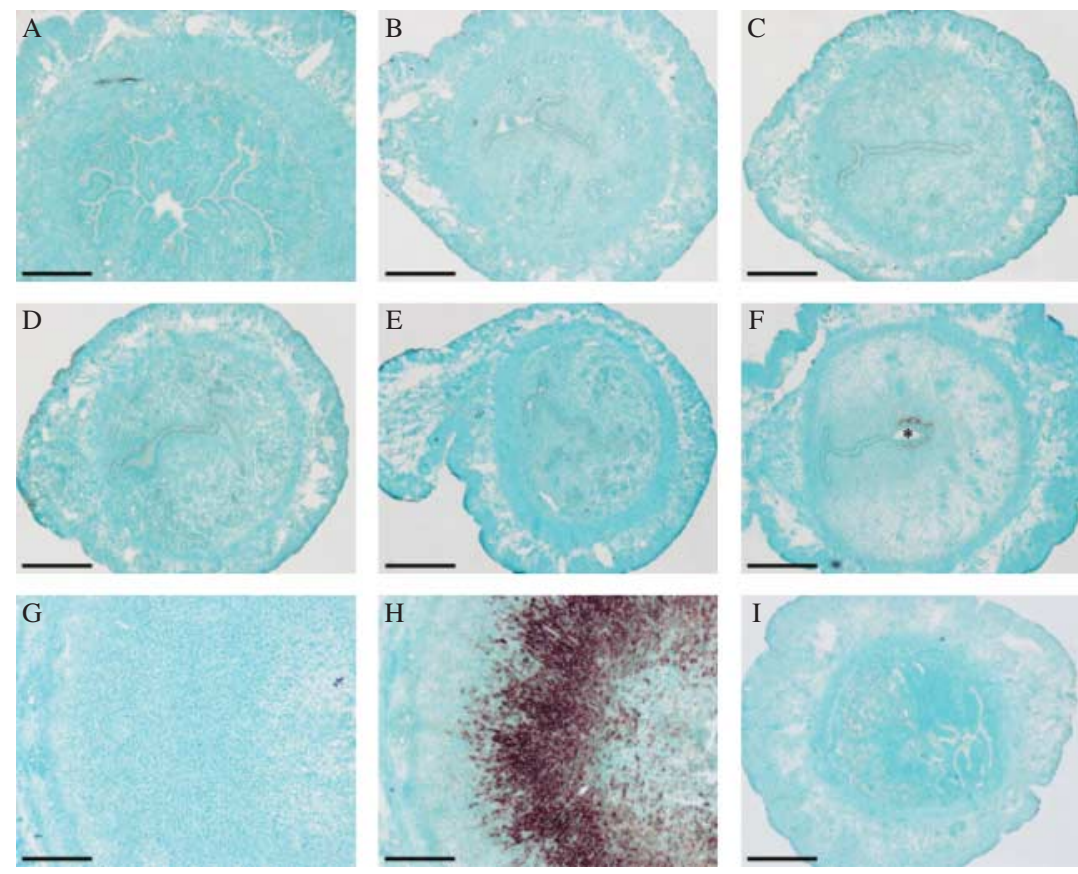

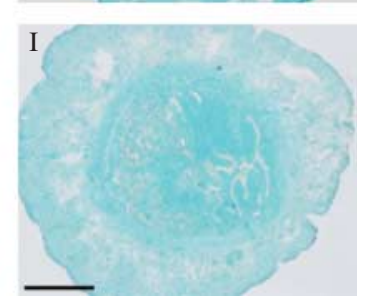

Figure 2 In situ hybridization of Cryab expression in mouse uteri during pseudopregnancy on days 1 (A), $3(\mathrm{~B}), 4(\mathrm{C})$, and $5(\mathrm{D})$, delayed implantation $(\mathrm{E})$ and activation $(\mathrm{F})$, artificial decidualization $(\mathrm{H})$, and contralateral uninjected uterine horn (I). No hybridization signals were seen in mouse uteri under artificial decidualization when DIG-labeled Cryab sense probe was used for in situ hybridization (G). Asterisks indicate embryo Bar $=60 \mu \mathrm{m}$. level of Cryab expression was detected in activated implantation uterus compared with the delayed uterus by real-time PCR (Fig. 3B).

\section{Cryab expression under artificial decidualization}

Because Cryab was strongly expressed in the decidua during early pregnancy, artificially induced decidualization was performed to see whether Cryab expression in the decidua was dependent on the presence of embryos. Under artificial decidualization, Cryab mRNA signal was strongly detected in the decidualized cells (Fig. 2H). However, no visible Cryab mRNA signal was found in uninjected control uterus (Fig. 2I). By real-time PCR analysis, Cryab expression was also significantly upregulated in the decidualized uterus compared with the control uterus (Fig. 3C).

\section{Cryab expression under in vitro decidualization}

Primary stromal cells isolated from mouse uteri on day 4 of pregnancy were treated with a combination of estrogen and progesterone to induce in vitro decidualization. Because prolactin family 8 , subfamily a, member 2 (Prl8a2) is a reliable marker for decidualization in mice, we examined whether Prl8a2 was expressed under in vitro decidualization. By real-time PCR analysis, the expression of Pr/8a2 was significantly upregulated from 24 to $96 \mathrm{~h}$ of culture (Fig. 4A), indicating that the method inducing in vitro decidualization was successful. Likewise, Cryab expression was also significantly elevated from 24 to $96 \mathrm{~h}$ after in vitro decidualization (Fig. 4B).

\section{cAMP regulation on Cryab expression}

Because CAMP is a key player in decidualization, the time course of Prl8a2 and Cryab expression was examined at $1,3,6,12$, and $24 \mathrm{~h}$ after the cultured uterine stromal cells were treated with 8-bromoadenosine-cAMP (8-Br-cAMP, Sigma). The results showed that Cryab expression was significantly higher at $6 \mathrm{~h}$, although 8-Br-cAMP could induce Cryab expression from 3 to $24 \mathrm{~h}$ of culture (Fig. 5B). Simultaneously, Prl8a2 expression gradually increased and reached the peak level at $24 \mathrm{~h}$ after 8-Br-cAMP treatment (Fig. 5A).

\section{Steroid hormonal regulation on Cryab expression}

As estrogen and progesterone are essential for mouse embryo implantation, ovariectomized mice were used to examine the effects of steroid hormones on Cryab expression. A low level of hybridization signal was seen in the uterus of ovariectomized mice (Fig. 6). Progesterone had no effect on Cryab expression, while estrogen could slightly induce the expression of Cryab mRNA in the luminal and glandular epithelium at $12 \mathrm{~h}$ (Fig. 6). By real-time analysis, Cryab mRNA expression increased in ovariectomized mice uteri after injection of estrogen and reached the highest level at $12 \mathrm{~h}$ (Fig. 7A). However, the upregulation of estrogen was significantly blocked by a pretreatment with ICI 182780 (Fig. 7D). In contrast, progesterone injection resulted in a decline in uterine Cryab mRNA levels, which reached a nadir by $24 \mathrm{~h}$ (Fig. 7B). A significantly higher level of Cryab expression was detected in the uterus of ovariectomized mice that had received injections of progesterone at $1 \mathrm{~h}$ 

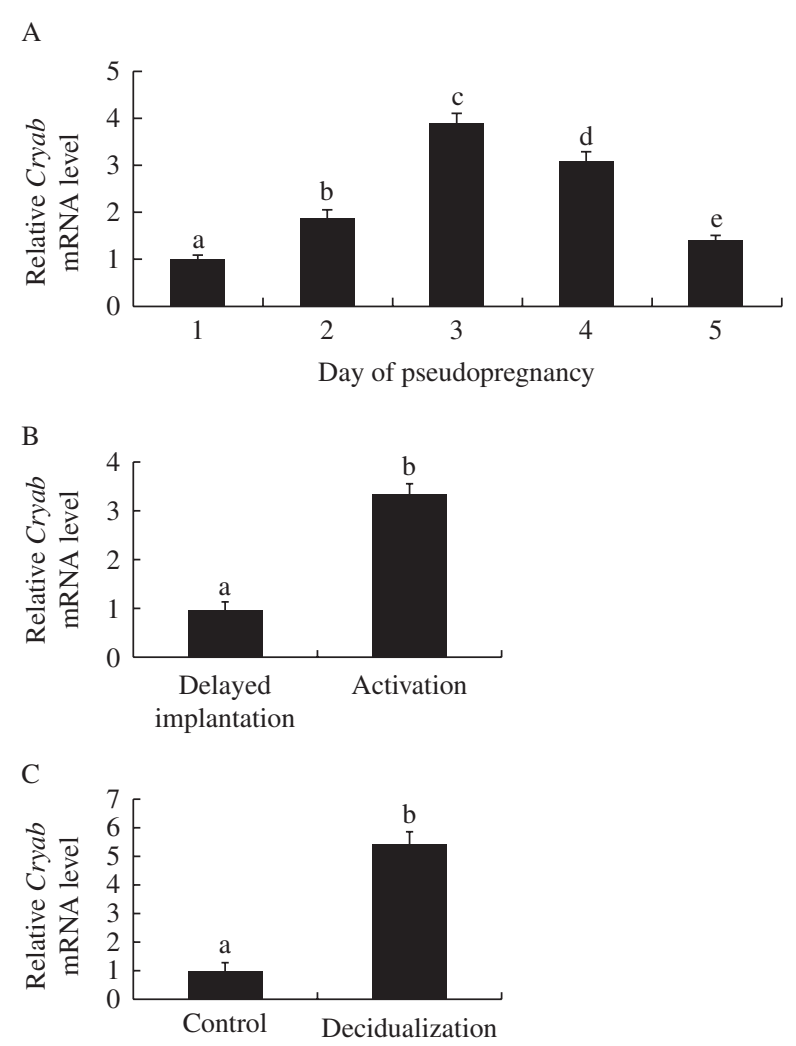

Figure 3 Cryab expression during pseudopregnancy, delayed and activated implantation, and artificial decidualization. (A) Real-time PCR analysis of Cryab expression in mouse uterus on days 1-5 during pseudopregnancy. (B) Real-time PCR analysis of Cryab expression in mouse uterus during delayed implantation and activation. (C) Real-time PCR analysis of Cryab expression under artificial decidualization. Data are shown as mean \pm S.E.M. Bars with different letters at the top differ significantly.

later after pretreatment of RU486 compared with that of progesterone treatment only (Fig. 7E). Additionally, a low level of Cryab expression was observed at $24 \mathrm{~h}$ after a combined injection of estrogen and progesterone (Fig. 7C).

In the in vitro-cultured stromal cells, Cryab mRNA expression was significantly induced at $24 \mathrm{~h}$ after treatment with estrogen or progesterone (Fig. $7 \mathrm{~F}$ and G). ICI 182780 could significantly reduce estrogenstimulated Cryab expression (Fig. 7F). A similar result was also observed with RU486 treatment (Fig. 7G).

\section{Discussion}

In this study, the expression and regulation of Cryab in mouse uterus during early pregnancy were examined by in situ hybridization and real-time PCR. Our results showed that Cryab mRNA signal from in situ hybridization was not detected in the mouse uteri from days 1 to 4 of pregnancy. Likewise, Cryab was also not seen in any of the proliferative endometrium from humans and baboons (Gruidl et al. 1997). However, Cryab mRNA was detected in mouse uterus using real-time PCR. The reason might lie in different sensitivity between real-time PCR and in situ hybridization. On day 5 of pregnancy when blastocysts implanted, a high level of Cryab mRNA signal was found in the subluminal stroma at implantation sites. No corresponding signals were observed at the interimplantation sites on day 5 of pregnancy or during pseudopregnancy. Simultaneously, a high level of Cryab expression was also detected in activated implantation uteri but not in delayed uteri. These results indicated that Cryab might play an important role in the process of mouse implantation and was influenced by the active blastocyst. In human endometrium, Cryab expression is upregulated during the window of implantation (Gruidl et al. 1997), which further supported a role for Cryab in implantation. Additional studies have found that Cryab could regulate angiogenesis by modulating the expression of vascular endothelial growth factor (VEGF), which was the main factor responsible for increased endometrial vascular permeability at implantation (Rabbani \& Rogers 2001, Rockwell et al. 2002, Kase et al. 2010, Ruan et al. 2011). Inhibition of VEGF could significantly reduce the number of implantation sites (Rabbani \& Rogers 2001, Rockwell et al. 2002, Guo et al. 2012). However, whether Cryab was capable of regulating VEGF in the

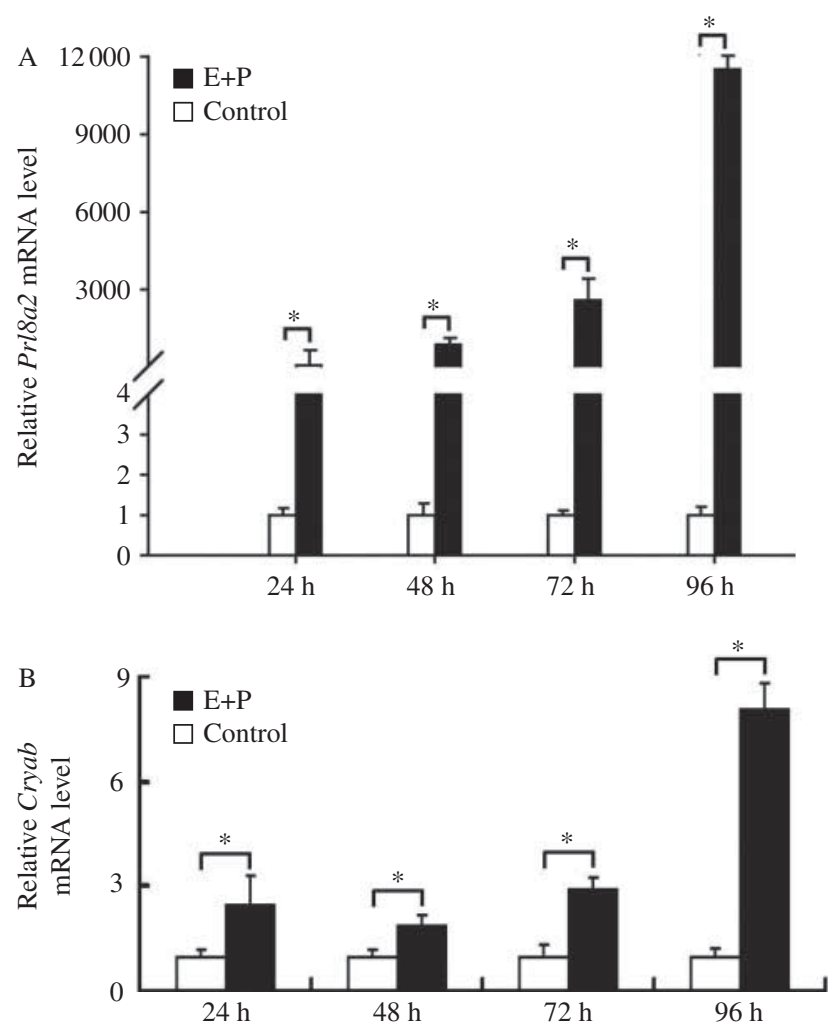

Figure 4 Real-time PCR analysis of Prl8a2 (A) and Cryab (B) expression in vitro decidualization of uterine stromal cells. Data are shown as mean \pm s.E.M. * Statistical significance $(P<0.05) ; \mathrm{E}$, estrogen; $\mathrm{P}$, progesterone. 

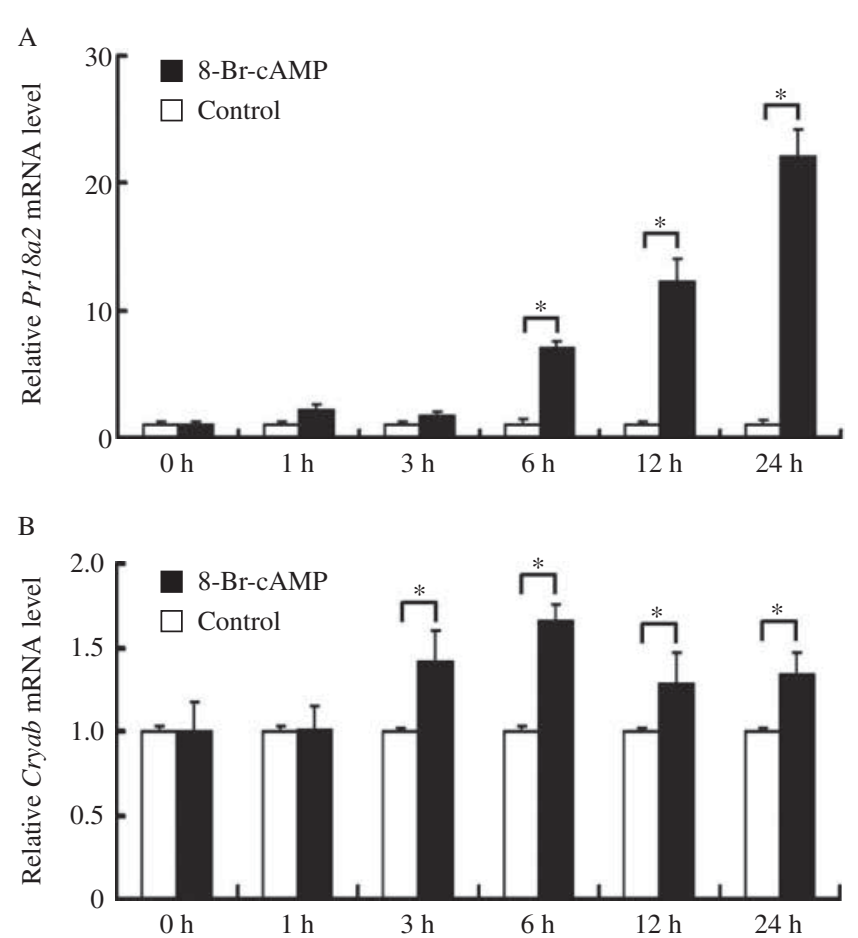

Figure 5 Effects of 8-Br-cAMP on Prl8a2 (A) and Cryab (B) expression in uterine stromal cells. Data are shown as mean \pm s.E.M. ${ }^{*}$ Statistical significance $(P<0.05)$

process of mouse implantation remained to be determined, although Cryab and VEGF are expressed in the subluminal stroma surrounding the implanting blastocyst (Chakraborty et al. 1995). Additionally,
Cryab could also regulate the expression of Trp53 (p53) gene (Watanabe et al. 2009). In Trp53-deficient female mice, the number of implantation sites was significantly reduced due to impaired uterine leukemia inhibitory factor (Lif) gene expression, which was critical for blastocyst implantation (Wang \& Dey 2006, Hu et al. 2007). Thus, we speculated that Cryab might play a role in the process of mouse implantation through influencing the expression of Trp53 and Lif genes.

Uterine stromal cell decidualization is integral to successful embryo implantation (Das 2009). Our results showed that Cryab mRNA signal was detected strongly in the decidua on days $6-8$ of pregnancy using real-time PCR and in situ hybridization. Likewise, the high level of Cryab mRNA could be detected in decidualized cells under artificial decidualization, and in the stromal cell cultures that were induced for in vitro decidualization. These results suggest that Cryab may play an important role during decidualization. A previous study found that cAMP levels significantly increased after sesame oil stimulation of the uterine horn (Rankin et al. 1977). Moreover, cAMP could induce and regulate the decidualization of uterine stromal cells (Gellersen \& Brosens 2003, Liang et al. 2010). In mouse uterine stromal cells cultured in vitro, we found that cAMP induced the expression of the Cryab gene, which further supports a role for Cryab in decidualization. Further study found that Cryab could promote angiogenesis during tube morphogenesis (Dimberg et al. 2008). Angiogenesis is crucial for decidualization because administration of AGM-1470 (a nonspecific angiogenesis
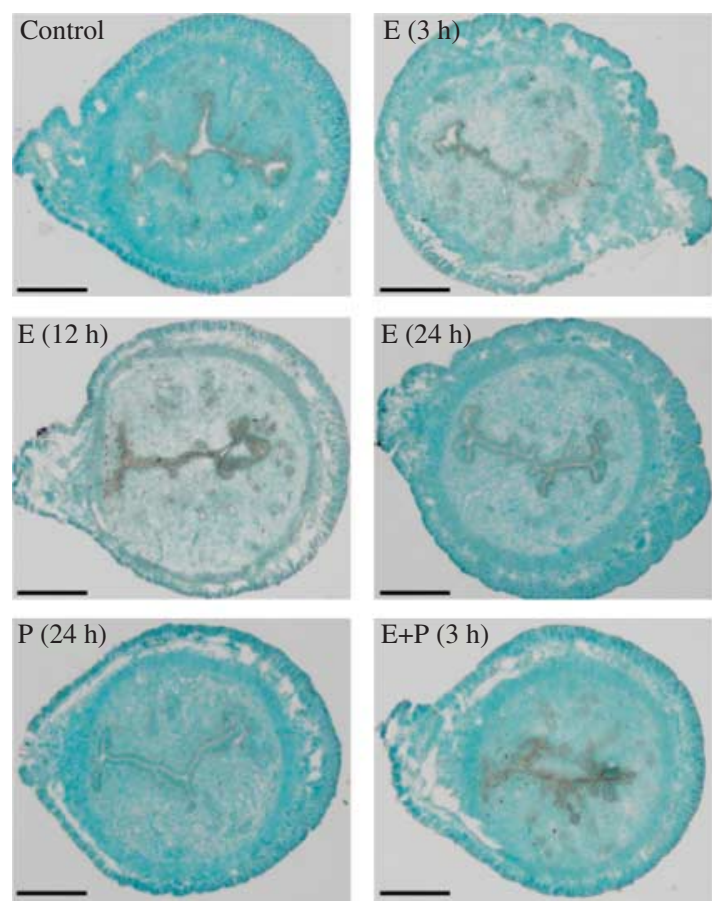
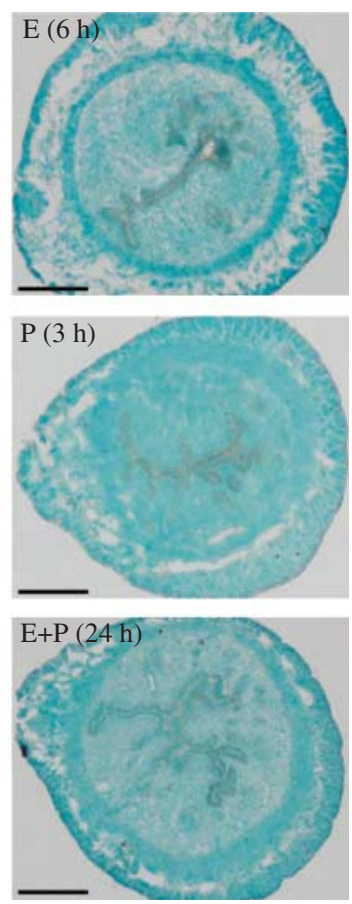

Figure 6 In situ hybridization of Cryab expression in ovariectomized mouse uteri after injection of estrogen, progesterone, or a combination of estrogen and progesterone for 0 (control), 1, 3, 6, 12, and $24 \mathrm{~h}$. Bar $=60 \mu \mathrm{m}$. E, estrogen; P, progesterone. 
A

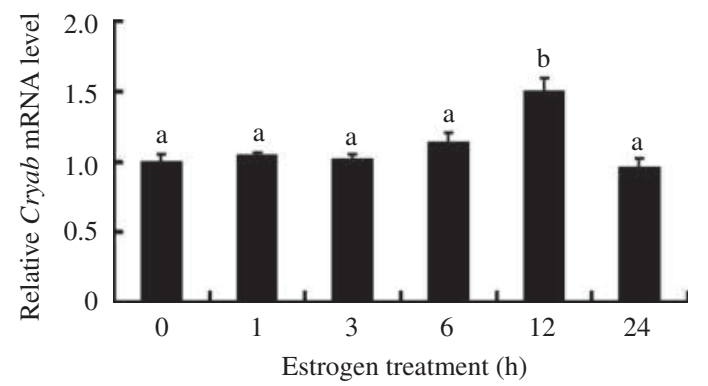

$\mathrm{C}$

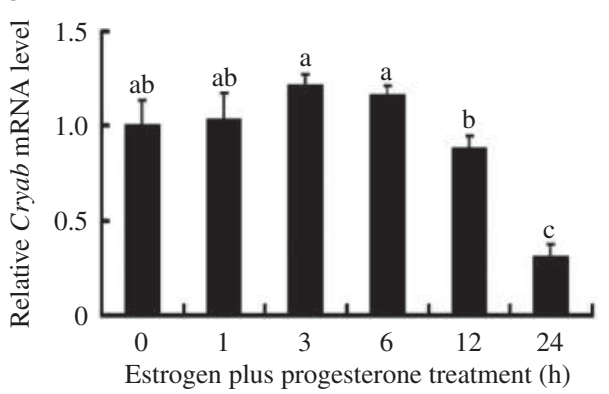

$\mathrm{F}$

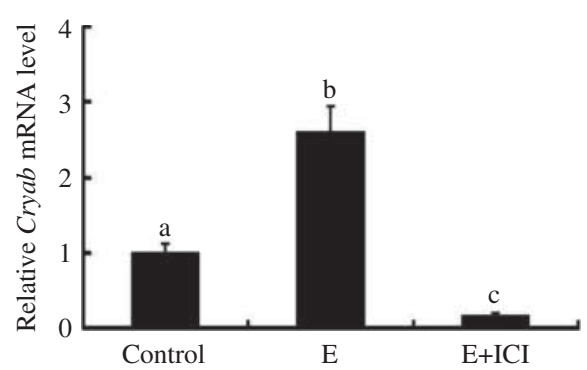

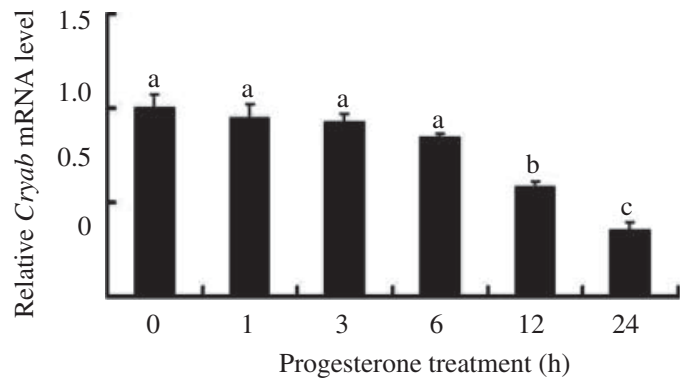

$\mathrm{E}$
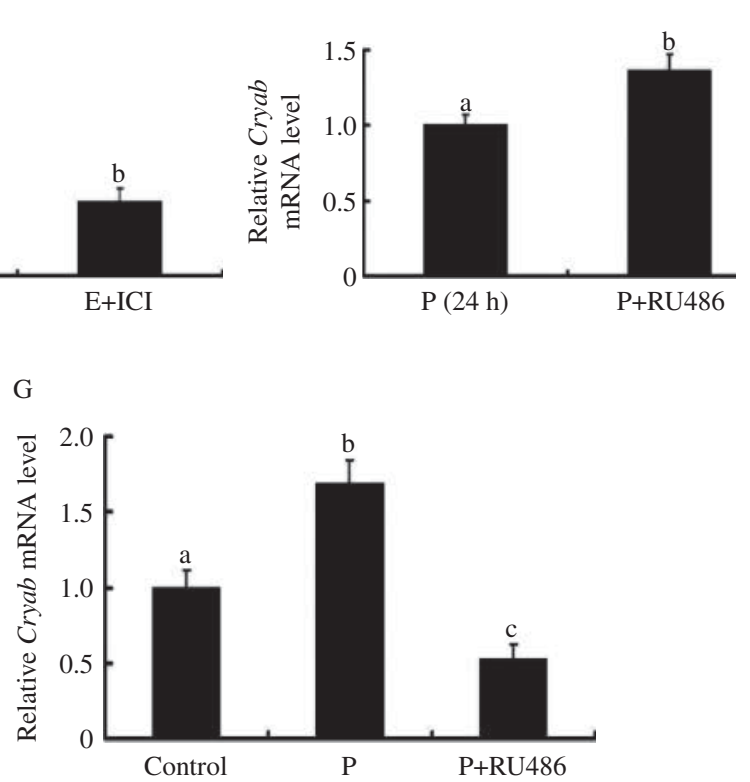

Figure 7 Hormonal regulation of Cryab expression. (A) Real-time PCR analysis of Cryab expression in ovariectomized mouse uterus after estrogen treatments for $0,1,3,6,12$, and $24 \mathrm{~h}$. (B) Cryab expression in ovariectomized mouse uterus after injection of progesterone. (C) Cryab expression in ovariectomized mouse uterus after injection of estrogen plus progesterone. (D) Cryab expression in ovariectomized mouse uterus after injection of estrogen and ICI 182 780. (E) Cryab expression in ovariectomized mouse uterus after injection of progesterone and RU486. (F) Cryab expression after stromal cells were treated with estrogen, or both estrogen and ICI 182 780. (G) Cryab expression after stromal cells were treated with progesterone, or both progesterone and RU486. Data are shown mean \pm s.E.M. Bars with different letters at the top differ significantly.

inhibitor) can result in impaired decidualization (Klauber et al. 1997, Guo et al. 2012). These data indicate that Cryab may direct uterine angiogenesis during decidualization.

Embryo implantation and decidualization are closely regulated by the ovarian estrogen and progesterone (Singh et al. 2011). On day 5 of pregnancy when the level of maternal estrogen was high, Cryab mRNA was highly expressed in mouse uterus, indicating that estrogen might be implicated in regulating the expression of Cryab gene. In the Cryab promoter region, there were multiple half-site estrogen-responsive elements (Frederikse et al. 1994, Gruidl et al. 1997). In this study, we also found that estrogen could upregulate the expression of Cryab mRNA in ovariectomized mouse uterus and uterine stromal cells. Moreover, the upregulation could be antagonized by estrogen receptor antagonist ICI 182780 , suggesting estrogen receptor requirement for this induction. In contrast, progesterone could inhibit Cryab expression through progesterone receptor in ovariectomized mouse uterus. In the uterine stromal cells cultured in vitro, Cryab expression was induced by progesterone. The discrepancies suggested that Cryab was also expressed in the other cell constituents of uterus where progesterone might inhibit Cryab expression. Indeed, Cryab has also been observed in the endometrial epithelial cells and muscle cells (Gruidl et al. 1997, Sanbe 2011). However, it is still to be determined whether progesterone could inhibit the expression of Cryab in the cells.

In conclusion, Cryab may be important for mouse embryo implantation and decidualization and regulated by estrogen and progesterone. 


\section{Materials and Methods}

\section{Animals}

Matured mice (Kunming White strain) were caged in a controlled environment with a cycle of $14 \mathrm{~h}$ light: $10 \mathrm{~h}$ darkness. All animal procedures were approved by the Institutional Animal Care and Use Committee of Jilin University. To confirm reproducibility of results, at least three mice per group were used in each stage or treatment in this study.

\section{Pregnancy and pseudopregnancy}

Adult female mice were mated with fertile or vasectomized males of the same strain to induce pregnancy or pseudopregnancy by co-caging respectively (day $1=$ day of vaginal plug). On days $1-4$, pregnancy was confirmed by recovering embryos from the oviducts or uterus. The implantation sites on day 5 were identified by i.v. injection of $0.1 \mathrm{ml} 1 \%$ Chicago blue (Sigma) in $0.85 \%$ sodium chloride.

\section{Delayed implantation and activation}

To induce delayed implantation, pregnant mice were ovariectomized under ether anesthesia at 0830-0900 h on day 4 of pregnancy. Progesterone ( $1 \mathrm{mg} /$ mouse; Sigma) was injected subcutaneously to maintain delayed implantation from days 5 to 7 . Estrogen ( $25 \mathrm{ng} /$ mouse, Sigma) was given to progesteroneprimed delayed-implantation mice to activate blastocyst implantation. The mice were killed to collect uteri $24 \mathrm{~h}$ after estrogen treatment. The implantation sites were identified by i.v. injection of Chicago blue solution. Delayed implantation was confirmed by flushing the blastocysts from the uterus.

\section{Artificial induced decidualization}

Artificial decidualization was induced by intraluminally infusing $25 \mu \mathrm{l}$ sesame oil into one uterine horn on day 4 of pseudopregnancy, while the contralateral uninjected horn served as a control. The uteri were collected on day 8 of pseudopregnancy. Decidualization was confirmed by weighing the uterine horn and by histological examination of uterine sections.

\section{Steroid hormonal treatments}

Mature female mice were ovariectomized and, after 2 weeks, given a single s.c. injection of estrogen (100 ng/mouse), progesterone ( $2 \mathrm{mg} / \mathrm{mouse})$, or a combination of the same doses of progesterone and estrogen (Guo et al. 2012). Uteri were then collected 1, 3, 6, 12, and $24 \mathrm{~h}$ after steroid treatment. To examine whether nuclear receptors for estrogen or progesterone are involved in steroid hormonal regulation, ovariectomized mice were injected with ICI 182780 (an estrogen receptor antagonist) or RU486 (a progesterone receptor antagonist) $1 \mathrm{~h}$ before estrogen or progesterone injection respectively. ICI 182780 and RU486 were injected at a dose of $500 \mu \mathrm{g}$ and $1 \mathrm{mg}$ per mouse respectively (Guo et al.
2012). All steroids and antagonists were dissolved in sesame oil and injected subcutaneously. Controls received the vehicle only $(0.1 \mathrm{ml} / \mathrm{mouse})$.

\section{In situ hybridization}

Total RNAs from the mouse uteri were reverse transcribed and amplified with Cryab primers. Cryab forward primer 5'-GGTTCTGGGGGACGTGATTG and reverse primer 5'-CAGCAGGCTTCTCTTCACGG were designed based on the sequence of the Mus musculus crystallin, alpha B gene (GenBank accession number NM_009964). The amplification of Cryab cDNA was performed with 30 cycles at $94{ }^{\circ} \mathrm{C}$ for $30 \mathrm{~s}$, $55^{\circ} \mathrm{C}$ for $30 \mathrm{~s}$, and $72{ }^{\circ} \mathrm{C}$ for $1 \mathrm{~min}$. The amplified fragment (230 bp) of Cryab was recovered from the agarose gel and cloned into pGEM-T plasmid (pGEM-T Vector System 1, Promega). The orientation of the Cryab fragment in the pGEM-T plasmid was determined by PCR using a combination of the primers for T7, SP6, and mouse Cryab. The cloned Cryab fragment was further verified by sequencing. Cryab-containing plasmid was amplified with the primers for T7 and S6 to prepare templates for labeling. Digoxigenin (DIG)-labeled antisense and sense cRNA probes were transcribed in vitro using a DIG RNA labeling kit (Roche Diagnostics $\mathrm{GmbH}$ ).

Frozen sections $(10 \mu \mathrm{m})$ were mounted on 3-aminopropyltriethoxysilane (Sigma)-coated slides and fixed in $4 \%$ paraformaldehyde solution in PBS. The sections were washed in PBS twice, treated with 1\% Triton-100 for $20 \mathrm{~min}$, and washed again in PBS three times. Following the prehybridization in the solution of $50 \%$ formamide and $5 \times$ SSC $(1 \times$ SSC is $0.15 \mathrm{M}$ sodium chloride, and $0.015 \mathrm{M}$ sodium citrate) at room temperature for $15 \mathrm{~min}$, the sections were hybridized in the hybridization buffer $(5 \times \mathrm{SSC}, 50 \%$ formamide, $0.02 \%$ BSA, $250 \mathrm{mg} / \mathrm{ml}$ yeast tRNA, $10 \%$ dextran sulfate, $1 \mathrm{mg} / \mathrm{ml}$ denatured DIG-labeled antisense, or sense RNA probe for mouse Cryab) at $55{ }^{\circ} \mathrm{C}$ for $16 \mathrm{~h}$. After hybridization, the sections were washed sequentially in $50 \%$ formamide $/ 5 \times$ SSC at $55^{\circ} \mathrm{C}$ for $15 \mathrm{~min}, 50 \%$ formamide/ $\times$ SSC at $55^{\circ} \mathrm{C}$ for $30 \mathrm{~min}, 50 \%$ formamide/ $0.2 \times \mathrm{SSC}$ at $55^{\circ} \mathrm{C}$ twice for $30 \mathrm{~min}$ each, and $0.2 \times$ SSC at room temperature for $5 \mathrm{~min}$. After nonspecific binding was blocked in $1 \%$ block reagent (Roche) for $1 \mathrm{~h}$, the sections were incubated in sheep anti-DIG antibody conjugated with alkaline phosphatase (1:5000, Roche) in 1\% block reagent overnight at $4{ }^{\circ} \mathrm{C}$ and then washed in buffer I (100 mM Tris- $\mathrm{HCl}, \mathrm{pH} 7.5$, and $150 \mathrm{mM} \mathrm{NaCl}$ ) three times for 5 min each before equilibration in Buffer II (100 mM Tris- $\mathrm{HCl}$, $\mathrm{pH} 9.5,100 \mathrm{mM} \mathrm{NaCl}$, and $50 \mathrm{mM} \mathrm{MgCl}_{2}$ ) for $5 \mathrm{~min}$. Endogenous alkaline phosphatase activity was inhibited with $2 \mathrm{mM}$ levamisole (Sigma). The signal was visualized with $0.4 \mathrm{mM}$ 5-bromo-4-chloro-3-indolyl phosphate and $0.4 \mathrm{mM}$ nitroblue tetrazolium in buffer II. All the sections were counterstained with $1 \%$ methyl green in $0.12 \mathrm{M}$ glacial acetic acid and $0.08 \mathrm{M}$ sodium acetate for $30 \mathrm{~min}$. The positive signal was visualized as a dark brown color.

\section{Real-time PCR}

Total RNAs from mouse uteri or cultured cells were isolated using TRIPURE reagent according to the manufacturer's 
instructions (Roche) and reverse transcribed into cDNA using M-MLV reverse transcriptase (Promega). Reverse transcription was performed at $42{ }^{\circ} \mathrm{C}$ for 60 min with $2 \mu \mathrm{g}$ total RNA in $25 \mu \mathrm{l}$ volume. For real-time PCR, cDNA was amplified using FS Universal SYBR Green Real Master (Roche) on BIO-RAD CFX96 Real Time Detection System. The conditions used for real-time PCR were as follows: $95{ }^{\circ} \mathrm{C}$ for $3 \mathrm{~min}$, followed by 40 cycles of $95{ }^{\circ} \mathrm{C}$ for $15 \mathrm{~s}$ and $60{ }^{\circ} \mathrm{C}$ for $1 \mathrm{~min}$. All reactions were run in triplicate. The result was analyzed using CFX Manager Software. After analysis using the $2^{-\Delta \Delta C t}$ method, data were normalized to Gapdh expression. Primer sequences for realtime PCR were as follows: Cryab (5'-CGGACTCTCAGAGATGCGTT and 5'-TGGGATCCGGTACTTCCTGT), Gapdh (5'-GCCTTCCGTGTTCCTACCC and 5'-TGCCTGCTTCACCACCTTC), and Prl8a2 (5'-AGCCAGAAATCACTGCCACT and 5'-TGATCCATGCACCCATAAAA).

\section{Isolation of uterine stromal cells}

Uterine stromal cells were isolated as previously reported (Liang et al. 2010). Briefly, uterine horns from day 4 pregnant mice were split longitudinally to expose the uterine lumen and digested in Hanks' balanced salt solution (HBSS) containing $1 \%$ trypsin (Amresco, Solon, OH, USA) and $6 \mathrm{mg} / \mathrm{ml}$ dispase (Roche). The digested uteri were shaken lightly to remove sheets of luminal epithelial cells. After the supernatant containing sheets of epithelial cells was discarded, the remaining tissues were washed three times with HBSS and incubated in HBSS containing $0.15 \mathrm{mg} / \mathrm{ml}$ collagenase I (Invitrogen) at $37{ }^{\circ} \mathrm{C}$ for $30 \mathrm{~min}$, followed by vigorous shaking until the supernatant became turbid. The supernatant was then passed through a $70 \mu \mathrm{m}$ wire gauze filter to eliminate epithelial sheets and centrifuged. The cell pellets were washed twice with HBSS and resuspended in complete medium consisting of DMEM-nutrient mixture F-12 Ham (DMEM-F12; Sigma) with $10 \%$ heat-inactivated fetal bovine serum (FBS; Life Technologies, Inc.). Viable cells were counted by trypan blue staining using a hemocytometer. Cells were plated onto $35 \mathrm{~mm}$ culture dishes at the concentration of $1 \times 10^{6}$ cells $/ \mathrm{ml}$. After an initial culture for $30 \mathrm{~min}$, the medium was changed to remove free-floating cells. The isolated stromal cells were further cultured in fresh complete medium at $37^{\circ} \mathrm{C}$ with $5 \% \mathrm{CO}_{2}$ before treatments.

\section{In vitro decidualization}

In vitro decidualization of endometrial stromal cells from day 4 of pregnancy was performed as described previously (Liang et al. 2010). Briefly, primary uterine stromal cells isolated on day 4 pregnancy were induced for in vitro decidualization with fresh medium supplemented with progesterone (100 nM) and estrogen $(0.1 \mathrm{nM})$ in DMEM-F12 with $2 \%$ charcoal-treated FBS (Biological Industries Ltd., Kibbutz Beit Hemeek, Israel).

\section{Steroid hormonal treatments in vitro}

Cultured stromal cells were treated with $100 \mathrm{nM}$ progesterone or $0.1 \mathrm{nM}$ estrogen. For further studies, cells were pretreated with RU486 $(1 \mu \mathrm{M})$ or $\mathrm{ICl} 182780(100 \mathrm{nM})$ before the addition of progesterone or estrogen respectively. Then cells were collected at $24 \mathrm{~h}$ for further quantitative analysis by realtime PCR. All steroids and antagonists were dissolved in ethanol. Controls received the vehicle only.

\section{Statistical analysis}

All the experiments were independently repeated at least three times. The significance of differences was analyzed by one-way ANOVA using the SPSS software program (SPSS, Inc.). The differences were considered significant at $P<0.05$.

\section{Declaration of interest}

The authors declare that there is no conflict of interest that could be perceived as prejudicing the impartiality of the research reported.

\section{Funding}

This work was financially supported by National Natural Science Foundation of China (31101778 and 31072099), Research Fund for the Doctoral Program of Higher Education of China (20100061110078), and '985' Platform Construction Foundation of Jilin University.

\section{References}

Bany BM \& Schultz GA 2001 Increased expression of a novel heat shock protein transcript in the mouse uterus during decidualization and in response to progesterone. Biology of Reproduction 64 284-292. (doi:10.1095/biolreprod64.1.284)

Brady JP, Garland D, Duglas-Tabor Y, Robison WG Jr, Groome A \& Wawrousek EF 1997 Targeted disruption of the mouse $\alpha \mathrm{A}$-crystallin gene induces cataract and cytoplasmic inclusion bodies containing the small heat shock protein $\alpha$ B-crystallin. PNAS 94 884-889. (doi:10.1073/pnas. 94.3.884)

Cakmak H \& Taylor HS 2011 Implantation failure: molecular mechanisms and clinical treatment. Human Reproduction Update 17 242-253. (doi:10.1093/humupd/dmq037)

Chakraborty I, Das SK \& Dey SK 1995 Differential expression of vascular endothelial growth factor and its receptor mRNAs in the mouse uterus around the time of implantation. Journal of Endocrinology 147 339-352. (doi:10.1677/joe.0.1470339)

Das SK 2009 Cell cycle regulatory control for uterine stromal cell decidualization in implantation. Reproduction 137 889-899. (doi:10.1530/ REP-08-0539)

Dimberg A, Rylova S, Dieterich LC, Olsson AK, Schiller P, Wikner C, Bohman S, Botling J, Lukinius A, Wawrousek EF et al. 2008 aB-crystallin promotes tumor angiogenesis by increasing vascular survival during tube morphogenesis. Blood 111 2015-2023. (doi:10.1182/blood-200704-087841)

Frederikse PH, Dubin RA, Haynes JI II \& Piatigorsky J 1994 Structure and alternate tissue-preferred transcription initiation of the mouse $\alpha \mathrm{B}$-crystallin/small heat shock protein gene. Nucleic Acids Research 22 5686-5694. (doi:10.1093/nar/22.25.5686)

Gellersen B \& Brosens J 2003 Cyclic AMP and progesterone receptor cross-talk in human endometrium: a decidualizing affair. Journal of Endocrinology 178 357-372. (doi:10.1677/joe.0.1780357)

Gruidl M, Buyuksal A, Babaknia A, Fazleabas AT, Sivarajah S, Satyaswaroop PG \& Tabibzadeh S 1997 The progressive rise in the expression of $\alpha$ crystallin B chain in human endometrium is initiated 
during the implantation window: modulation of gene expression by steroid hormones. Molecular Human Reproduction 3 333-342. (doi:10.1093/molehr/3.4.333)

Guo B, Wang W, Li SJ, Han YS, Zhang L, Zhang XM, Liu JX \& Yue ZP 2012 Differential expression and regulation of angiopoietin-2 in mouse uterus during preimplantation period. Anatomical Record 295 338-346. (doi:10.1002/ar.21494)

Hu W, Feng Z, Teresky AK \& Levine AJ 2007 p53 regulates maternal reproduction through LIF. Nature 450 721-724. (doi:10.1038/nature05993)

Kase S, He S, Sonoda S, Kitamura M, Spee C, Wawrousek E, Ryan SJ, Kannan R \& Hinton DR 2010 aB-crystallin regulation of angiogenesis by modulation of VEGF. Blood 115 3398-3406. (doi:10.1182/blood-200901-197095)

Klauber N, Rohan RM, Flynn E \& D'Amato RJ 1997 Critical components of the female reproductive pathway are suppressed by the angiogenesis inhibitor AGM-1470. Nature Medicine 3 443-446. (doi:10.1038/ nm0497-443)

Klein C, Scoggin KE, Ealy AD \& Troedsson MH 2010 Transcriptional profiling of equine endometrium during the time of maternal recognition of pregnancy. Biology of Reproduction 83 102-113. (doi:10.1095/ biolreprod.109.081612)

Liang XH, Zhao ZA, Deng WB, Tian Z, Lei W, Xu X, Zhang XH, Su RW \& Yang ZM 2010 Estrogen regulates amiloride-binding protein 1 through CCAAT/enhancer- binding protein- $\beta$ in mouse uterus during embryo implantation and decidualization. Endocrinology 151 5007-5016. (doi:10.1210/en.2010-0170)

Mainz A, Bardiaux B, Kuppler F, Multhaup G, Felli IC, Pierattelli R \& Reif B 2012 Structural and mechanistic implications of metal binding in the small heat-shock protein $\alpha \mathrm{B}$-crystallin. Journal of Biological Chemistry 287 1128-1138. (doi:10.1074/jbc.M111.309047)

MerkI M, Ulbrich SE, Otzdorff C, Herbach N, Wanke R, Wolf E, Handler J \& Bauersachs S 2010 Microarray analysis of equine endometrium at days 8 and 12 of pregnancy. Biology of Reproduction 83 874-886. (doi:10.1095/biolreprod.110.085233)

Mineva I, Stamenova M, Gartner W \& Wagner L 2008 Expression of the small heat shock protein $\alpha \mathrm{B}$-crystallin in term human placenta. American Journal of Reproductive Immunology 60 440-448. (doi:10.1111/j.16000897.2008.00642.x)

Neuer A, Spandorfer SD, Giraldo P, Dieterle S, Rosenwaks Z \& Witkin SS 2000 The role of heat shock proteins in reproduction. Human Reproduction Update 6 149-159. (doi:10.1093/humupd/6.2.149)

Rabbani ML \& Rogers PA 2001 Role of vascular endothelial growth factor in endometrial vascular events before implantation in rats. Reproduction 122 85-90. (doi:10.1530/rep.0.1220085)
Rankin JC, Ledford BE \& Baggett B 1977 Early involvement of cyclic nucleotides in the artificially stimulated decidual cell reaction in the mouse uterus. Biology of Reproduction 17 549-554. (doi:10.1095/ biolreprod17.4.549)

Robinson ML \& Overbeek PA 1996 Differential expression of $\alpha \mathrm{A}$ and $\alpha \mathrm{B}$-crystallin during murine ocular development. Investigative Ophthalmology \& Visual Science 37 2276-2284.

Rockwell LC, Pillai S, Olson CE \& Koos RD 2002 Inhibition of vascular endothelial growth factor/vascular permeability factor action blocks estrogen-induced uterine edema and implantation in rodents. Biology of Reproduction 67 1804-1810. (doi:10.1095/biolreprod.102. 006700)

Ruan Q, Han S, Jiang WG, Boulton ME, Chen ZJ, Law BK \& Cai J 2011 $\alpha \mathrm{B}$-crystallin, an effector of unfolded protein response, confers antiVEGF resistance to breast cancer via maintenance of intracrine VEGF in endothelial cells. Molecular Cancer Research 9 1632-1643. (doi:10.1158/1541-7786.MCR-11-0327)

Sanbe A 2011 Molecular mechanisms of $\alpha$-crystallinopathy and its therapeutic strategy. Biological \& Pharmaceutical Bulletin 34 1653-1658. (doi:10.1248/bpb.34.1653)

Singh M, Chaudhry P \& Asselin E 2011 Bridging endometrial receptivity and implantation: network of hormones, cytokines, and growth factors. Journal of Endocrinology 210 5-14. (doi:10.1530/JOE-10-0461)

Tabibzadeh S \& Broome J 1999 Heat shock proteins in human endometrium throughout the menstrual cycle. Infectious Diseases in Obstetrics and Gynecology 7 5-9. (doi:10.1155/S1064744999000022)

Wang H \& Dey SK 2006 Roadmap to embryo implantation: clues from mouse models. Nature Reviews. Genetics 7 185-199. (doi:10.1038/ nrg1808)

Watanabe G, Kato S, Nakata H, Ishida T, Ohuchi N \& Ishioka C 2009 $\alpha \mathrm{B}$-crystallin: a novel p53-target gene required for p53-dependent apoptosis. Cancer Science 100 2368-2375. (doi:10.1111/j.1349-7006. 2009.01316.x)

Yuan JX, Xiao LJ, Lu CL, Zhang XS, Liu T, Chen M, Hu ZY, Gao F \& Liu YX 2009 Increased expression of heat shock protein 105 in rat uterus of early pregnancy and its significance in embryo implantation. Reproductive Biology and Endocrinology 7 23. (doi:10.1186/1477-7827-7-23)

Received 4 February 2013

First decision 11 March 2013

Accepted 10 April 2013 